** This is the accepted version. Please cite the published version. **

\title{
UNTYING THE GORGIANIC 'NOT': ARGUMENTATIVE STRUCTURE IN ON NOT-BEING ${ }^{1}$
}

Gorgias' On Not-Being survives only in two divergent summaries. Diels-Kranz's classic edition prints the better-preserved version that appears in Sextus' Adversus Mathematicos. Yet in recent years there has been rising interest in a second summary that survives as part of the anonymous De Melisso, Xenophane, Gorgia. The text of the $M X G$ is more difficult; it contains substantial lacunae that often make it much harder to make grammatical let alone philosophical sense of. As Alexander Mourelatos reports, one manuscript has scribal note that reads: 'The original contains many errors; no one should blame me; I just copy what I see.'2 The treatise's state of preservation has aptly prompted Michael Gagarin to liken it to a black hole: 'something we cannot see directly but know must exist because of certain effects it has on other objects. ${ }^{3}$

${ }^{1}$ Many thanks to Verity Harte, Rachel Barney, Ken Winkler, and David Charles for helpful comments on an earlier version of this paper. Thanks also to an anonymous reviewer for several helpful suggestions for improvement, as well as to Michael Gagarin for productive conversations about argumentative structure in Gorgias' works.

${ }^{2}$ A. Mourelatos, 'Gorgias on the Function of Language', Philosophical Topics 15 (1987), $135-70$ at 164 n.3.

${ }^{3}$ M. Gagarin, 'On the Not-Being of Gorgias's “On Not-Being” (ONB)', Philosophy \& Rhetoric 30 (1997), 38-40 at 40. 
Scholarship on On Not-Being often begins by privileging one of the two treatises as more accurate and working from there. ${ }^{4}$ The $M X G$ has recently been preferred in part for its likely preserving more of Gorgias' original language. ${ }^{5}$ But the idea of a single

${ }^{4}$ The extreme version of this tendency is Diels-Kranz' decision not even to print the $M X G$. A more recent example on the other side is J. Mansfeld, 'Historical and Philosophical Aspects of Gorgias' "On What Is Not", reprinted in Studies in the Historiography of Greek Philosophy (Assen, 1990), 97-125. Mansfeld cites a number of recent scholars who, like himself, consider the $M X G$ to be more reliable (n.4, at 97). As a result, he only refers to Sextus 'for some points of detail' (98). Mourelatos largely follows suit calling the $M X G$ 'unquestionably' the better source for the second part of the treatise (136). He does quote from Sextus, but again only to supplement his findings from the $M X G$; even with regards to passages that are preserved only by Sextus he is less than enthusiastic stating merely that 'it is perhaps not impossible to recover behind that Hellenistic encrustation a recognizably Gorgianic thought' (158). Likewise V. Caston, 'Gorgias on Thought and its Objects', in D.W. Graham and V. Caston (edd.), Presocratic philosophy: essays in honour of Alexander Mourelatos (Aldershot, 2002), 205-32 is largely dismissive of the evidence from Sextus and relies on it only tentatively and infrequently (e.g. 222, 224, 229). Gagarin also notes that the $M X G$ is the current favourite among translators (38).

${ }^{5}$ Much of the language Sextus uses is only attested in authors much later than Gorgias himself, whereas the language of the $M X G$ is consistent with other works of the fourth and fifth centuries B.C.E. See G.B. Kerferd, 'Gorgias on Nature or That Which Is Not', Phronesis 1 (1955), 3-25 at 14; G. Calogero, Studi sull'Eleatismo (Florence, 1977²), n.4 
preferred paraphrase creates a false dichotomy; it may very well be that each paraphrase is closer to the original in different respects. I will show how an independent and charitable reading of both versions suggests that, while the $M X G$ may indeed preserve more of Gorgias' language, Sextus preserves more of the original argument's structure.

One striking similarity is that both paraphrases explicitly split the argument into three parts: one arguing that nothing is, the second that even if it is it cannot be cognized, and the third that even if it can be cognized it cannot be communicated (Sextus 65, $M X G$ 979a12-13). I will focus on the first part, which preserves some of the most interesting material from a methodological perspective. This will help correct for the recent bias towards the $M X G$ and for the relative neglect of the first part since Kerferd's 1955 article. $^{6}$ I will show that there is a pattern of argumentation found throughout Gorgias' works that is better represented by Sextus and explain how the difference between the two versions arose from a simple mistake made by the author of the $M X G .^{7}$ This suggests

at 158; and H. Diels, Aristotelis qui fertur de Melisso Xenophane Gorgia libelius (Berlin, 1900), at 10. For a case study concerning the third part of the treatise see R.N. Gaines, 'Knowledge and Discourse in Gorgias's "On the Non-Existent or On Nature", Philosophy \& Rhetoric 30 (1997), 1-12.

${ }^{6}$ Kerferd goes to great lengths to argue that the $M X G$ preserves the same argument as Sextus does in the first part, though I will argue that they do differ in at least one crucial respect. Caston and Mourelatos give detailed analyses of the second and third part respectively, but set the first part aside.

7 I will follow J. Mansfeld, 'De Melisso Xenophane Gorgia: Pyrrhonizing Aristotelianism', Rheinisches Museum für Philologie 131 (1988), 239-76 in referring to 
that Sextus deserves more attention than he has received in the recent literature insofar as he more accurately preserves the structure of Gorgias' argument, though it does not preclude the likelihood that the $M X G$ is more accurate in other respects.

\section{$\S 1$ : THE PATTERN}

The structure of the argument in the first part of On Not-Being is an instance of a general pattern found throughout Gorgias' extant works. He often makes an exhaustive division then shows how each possibility points towards a single conclusion, allowing him to show how no matter which way you go his desired result follows. The two characteristic features of this strategy are (a) the use of exhaustive polylemmata, ${ }^{8}$ and (b) the primary aim of establishing the truth of some desired consequence of each lemma rather than the truth of the lemma itself. Related to the first characteristic is (c) the nesting of one polylemma within another. In this section I briefly establish this pattern as it appears in the Helen and Palamedes. In the next section I offer independent analyses of each paraphrase of On Not-Being that reveal how Sextus' version preserves the same pattern, one that is strikingly similar to the Palamedes in particular.

\section{§1.1: The Helen}

the author of the $M X G$ as 'Anonymous'. Anonymous is standardly referred to with a masculine pronoun; while it is mere conjecture that the author would have been male, this is unfortunately all too likely given the long history of sexism.

${ }^{8}$ By 'polylemma' I simply mean a division into two or more possibilities, which can be represented as a disjunction with two or more disjuncts. 
The argument of the Helen clearly employs the pattern of using what is taken to be an exhaustive polylemma with an eye to establishing the same positive conclusion in each case. ${ }^{9}$ This is an argument by cases, a species of the general pattern described above where a positive conclusion is derived from each lemma. The argument spans the entire work, introducing the goal of exonerating Helen in (2) and announcing the successful completion of that goal in (21).

The main polylemmatic structure of the argument becomes clear in (5)-(6):

(5)... I will proceed to the beginning of the ensuing speech, and I will set forth the causes on account of which it was likely ${ }^{10}$ for Helen's expedition to Troy to come about. (6) For either she did the things she did by the will of Fate and the

\footnotetext{
${ }^{9}$ For an argument to fit the pattern discussed here, the polylemma need only be taken to be exhaustive. The argument will only be sound, however, if the polylemma truly is exhaustive. I will suggest that the relevant polylemma in the Helen is portrayed as exhaustive and taken to be so for the sake of the argument, though this is ultimately a mistake (perhaps even a self-conscious one on Gorgias' part).

${ }^{10}$ See M. Gagarin and P. Woodruff, 'The Sophists', in P. Curd and D.W. Graham (edd.), The Oxford Handbook of Presocratic Philosophy (Oxford, 2008), 365-82 for translating ¿ǐcós with a normative valence. In general they recommend 'reasonable' as an English translation, which Spatharas adopts for this case in D.G. Spatharas, 'Gorgias: an edition of the extant texts and fragments with commentary and introduction' (Diss., University of Glasgow, 2001). Yet here 'reasonable' is misleading since Gorgias is not enumerating cases that would make Helen's action rational. For this reason, 'likely' is better in this instance.
} 
resolution of the gods and the decrees of Necessity, or having been snatched up by force, or persuaded by speeches, <or seized by love $>.{ }^{11}$

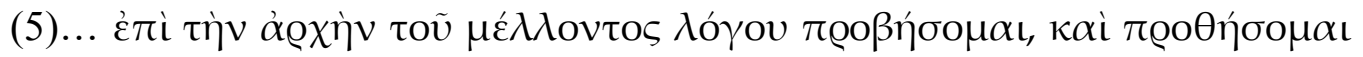

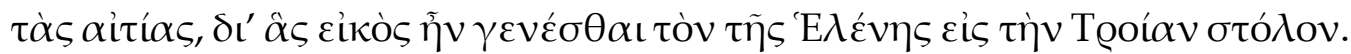

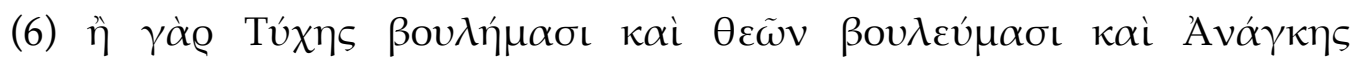

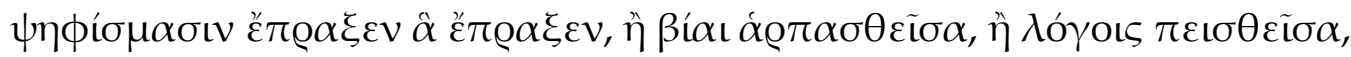

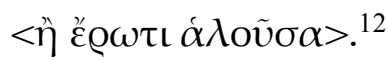

${ }^{11}$ I am including the medieval conjecture accepted by most modern commentators. The text as it is transmitted does not mention the fourth possibility, but Gorgias transitions to it in (15) in a way that suggests it was understood to have already been mentioned, stating simply: 'and I will go through the fourth cause with the fourth argument' (ìे $\delta \dot{\varepsilon}$

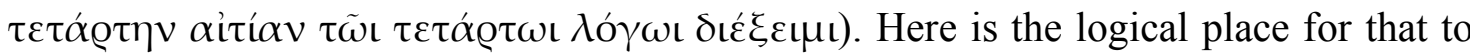
have happened. It also fits well with the mention of this option in the final summary quoted immediately below.

${ }^{12}$ All translations are my own and based off of the Greek text of DK with more recent texts and translations consulted in addition. The following were particularly useful. Those including all of Gorgias' works are Spatharas' commentary; D.W. Graham (ed.), The Texts of Early Greek Philosophy: The Complete Fragments and Selected Testimonies of the Major Presocratics (Cambridge, 2010), 740-50; T. Buchheim (ed.), Reden, Fragmente Und Testimonien (Hamburg, 1989²), 39-64; and M. Untersteiner, Sofisti: Testimonianze E Frammenti (Florence, 1949), 36-74. In addition, B. Cassin, Si Parménide: Le Traité Anonyme De Melisso, Xenophane, Gorgia (Lille, 1980) and H. Diels, Aristotelis qui fertur De Melisso Xenophane Gorgia libellus (Berlin, 1900) contain 
and again when the argument is summarized in (20):

(20) So how could one regard the blame of Helen as just, being someone who was either in love or persuaded by speech or snatched up by force or compelled by divine compulsion when she did the things she did, escaping the charge in every way?

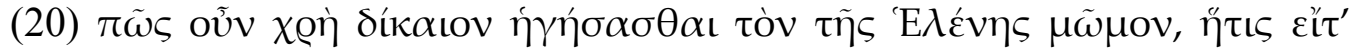

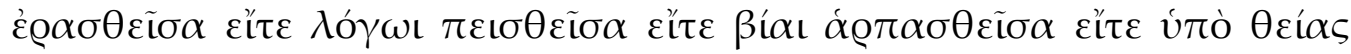

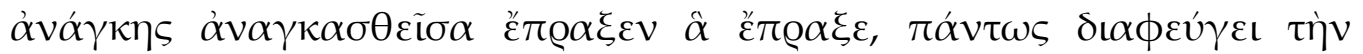

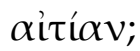

As these two summaries make clear, the argument operates by articulating four possibilities and examining each one in turn. This is precisely what happens in the intervening fourteen sections. Gorgias first examines the case of divine compulsion (6), then force (7), speech (8-14), and love (15-19), showing that Helen is not to be blamed in each case. Thus it has the structure of a fourfold polylemma.

It is also clear that Gorgias presents the polylemma as an exhaustive one. The division must be exhaustive (that is, on the assumption that Helen did in fact go to Troy)

the $M X G$ version of On Not-Being. For the Helen, D. MacDowell, Encomium of Helen (Bristol, 1982) was also consulted, as were the translations of J.M. Dillon and T. Gergel, The Greek Sophists (New York, 2009) and M. Gagarin and P. Woodruff, Early Greek Political Thought from Homer to the Sophists (Cambridge, 1995). 
for the argument to be valid, and Gorgias does treat it as a valid argument. ${ }^{13}$ Gorgias begins by clearly laying out the aim of the argument in (2):

(2)... Adding some reasoning to my speech, I would like to protect the woman being spoken of badly from the charge, to reveal those blaming her as liars, and both to show the truth and hold them back from ignorance.

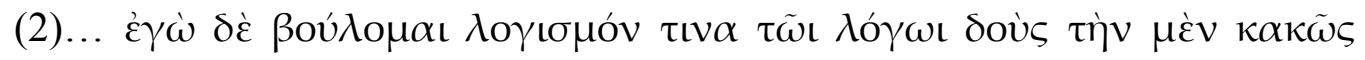

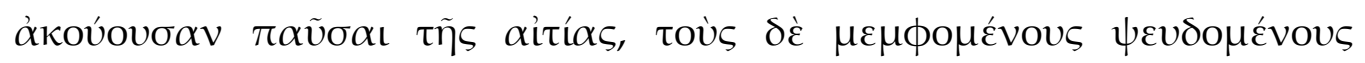

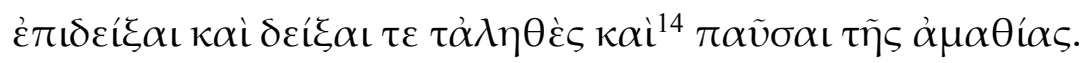

At the end he explicitly refers back to this goal as having been achieved:

(21) I removed the disrepute of a woman through speech, sticking to the resolution which I set forth at the beginning of my speech...

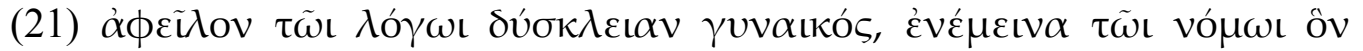

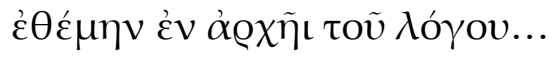

13 Cf. J. Barnes, The Presocratic Philosophers (New York, 1982) at 416. I will distinguish strictly exhaustive polylemmata, which cover all possibilities, from polylemmata that are conditional on some other possibility obtaining. Most of the polylemmata used by Gorgias are conditional in this sense.

14 Following MacDowell's reconstruction of the text (cf. 'Gorgias, Alkidamas, Cripps and Palatine Manuscripts' 120-121). The manuscripts read $\eta$ rather than $\kappa \alpha i$. 
These statements would not make sense unless, at least at some level, Gorgias takes himself to be giving a compelling argument. In so far as the argument is meant as an argument at all, then, we should read it as offering an exhaustive division. ${ }^{15}$

Gorgias' introductory and concluding statements also show how his aim is not to establish which of the four possibilities actually obtained, but rather to establish what follows from each: Helen is not to be blamed. Thus the argument of the Helen also meets the second characteristic feature of this recurring pattern. I agree with Barney's reconstruction as follows:

(1) Helen went to Troy either because of fate and the gods (I here simplify 'the will of fortune and the plan of the gods and the decree of necessity') or because of force or because of persuasion by speech [logos] or because of erōs.

(2) If she went to Troy because of fate and the gods, Helen is not to blame.

(3) If she went to Troy because she was forced, Helen is not to blame.

(4) If she went to Troy because she was persuaded by logos, Helen is not to blame.

(5) If she went to Troy because of erōs, Helen is not to blame.

(6) Therefore, Helen is not to blame for going to Troy (from $1+2+3+4+5$ ).

(Barney, at 5)

${ }^{15}$ While we are meant to initially take the argument as exhaustive, the fact that the argument appears to generalize such that no one is ever to blame, and that Gorgias ends by calling it an amusement ( $\pi \alpha \hat{i} \gamma \nu$ เov), may indicate that we are meant to question whether it really did cover all of the relevant possibilities in the first place. For further discussion of this point see R. Barney, 'Gorgias' Encomium of Helen', in E. Schliesser (ed.), Ten Neglected Classics of Philosophy (Oxford, 2016), 1-25. 
Furthermore, the Helen briefly exhibits a third element that is found in Gorgias' other works. When discussing the case of love, Gorgias makes another dilemmatic split: love is either the pleasing effect of a beautiful body, or a god. But still, either way Helen is not to blame (19). This nesting of one polylemma within another appears time and again in the Palamedes and the first part of On Not-Being as well. I have included a visual diagram of the argument's structure in an appendix for easy comparison with the arguments of the Palamedes and On Not-Being.

\section{§1.2: The Palamedes}

The same pattern of employing an exhaustive polylemma with a focus of deriving some desired conclusion in each case is even more prevalent in the Palamedes. The same goes for the further pattern of nested polylemmata. One difference is that the Palamedes is often focussed on deriving a negative consequence from each lemma rather than a positive one. When the polylemma is conditional on some other possibility obtaining, this then serves as a reductio of that possibility. The following is a simple example: suppose that if I had gone to the mountains I would have either walked, biked, or taken a train. Now suppose that each option would have been impossible. On this basis, we can conclude that I must not have gone to the mountains. As opposed to the argument by cases in the Helen, I will call this specific pattern a 'conditional polylemmatic reductio'.

Being a defence speech, the implicit aim of the Palamedes is to argue that Palamedes should not be sentenced to death. Gorgias has Palamedes undertake three different argumentative strategies throughout the speech to establish this main conclusion. The first is to establish that he is not guilty by showing that he could not have been both willing and able to commit the crime (6-21). The second is to undermine Odysseus' trustworthiness as a witness (22-32). Finally, he argues that a summary 
judgment would be overly hasty in this case (33-6). For present purposes I will focus on the first strategy, which proceeds by a series of conditional polylemmatic reductiones.

The initial strategy can be further subdivided into two alternative sets of arguments, arguments for the claim (a) that Palamedes would not have been able, and arguments for the claim (b) that Palamedes would not have been willing. This much is implicit in the way Gorgias has Palamedes set it up:

(5)... But if he [Odysseus] made the charge thinking that things were thus, I will show that he doesn't speak the truth in two ways: for if I had been willing I wouldn't have been able, nor had I been able would I have been willing to attempt such deeds.

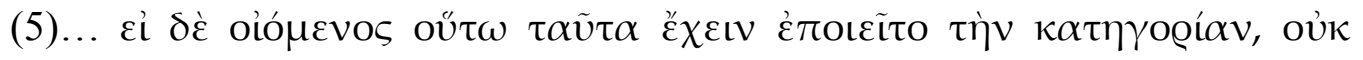

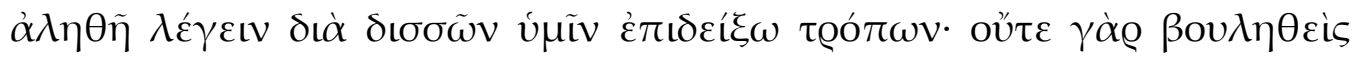

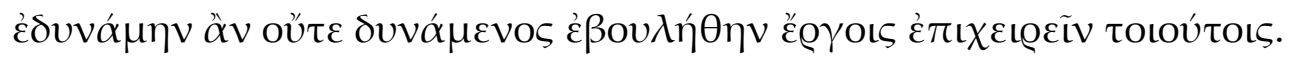

Thus the first set of arguments for (a) have the following form:

(i) if Palamedes were guilty of the crime, then he must have been both willing and able,

(ii) but he would not have been able, [claim (a)]

(iii) therefore, he is not guilty.

And the second set of arguments for (b) have the related form:

(i) if Palamedes were guilty of the crime, then he must have been both willing and able,

(ii) but he would not have been willing, [claim (b)] 
(iii) therefore, he is not guilty.

These arguments have a concessive structure that allows Palamedes to accommodate potential objections: he can grant his opponent that he was willing, for instance, but still show that even granting this he would not have been able. This technique appears in the structure of On Not-Being as well.

There are ten arguments for the conclusion that Palamedes would not have been able to commit treason $(6-12,21)$. They stand out for the nested, polylemmatic reductio structure they create: Palamedes tends to split the space of possibilities into multiple options, rule out every option but one, then repeat by splitting the last option into more possibilities, etc. Even then he grants one of the previously ruled-out possibilities for the sake of argument and proceeds to give another nested polylemmatic reductio. Thus the overarching structure is a conditional polylemmatic reductio, the conclusion being that the initial premise (that Palamedes was able) is to be rejected.

The way the argument is introduced makes it clear that this is a reductio against the possibility of Palamedes committing treason:

(6) I will now proceed to the first argument, that I am incapable of doing this. For some first beginning of the treason would have needed to come about, and that first beginning would have been a discussion...

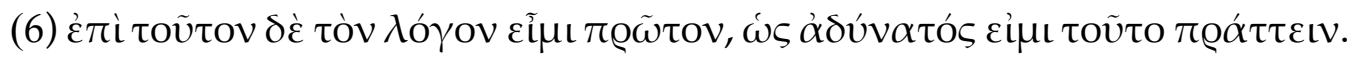

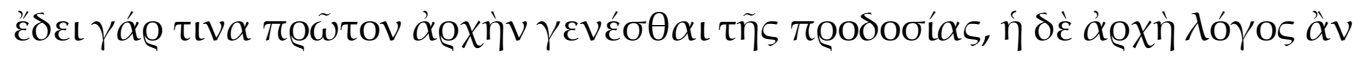

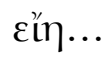


The imperfect $\check{\varepsilon} \delta \varepsilon \iota$ is important. It extends the counterfactual reasoning begun in the previous section (again expressed with the imperfect). ${ }^{16}$ But it is natural to ask: a first beginning would have needed to come about... if what? The suppressed premise must be 'if it had been possible'. ${ }^{17}$ Thus the implicit structure here is:

${ }^{16}$ As Smyth notes under 'Present and Past Unreal Conditions': 'the imperfect refers to present time or (sometimes) to a continued or habitual past act or state' (Smyth, 2304). The imperfect here is the appropriate tense for Palamedes' state of inability that is presumed to be continuous from that past time up through the present moment of his speech.

${ }^{17}$ This fits best with the imperfect and with the structure of the ensuing argument of the Palamedes. If the suppressed premise were instead 'if it had happened...', as suggested in A.A Long, Methods of Argument in Gorgias, Palamedes' H APXAIA $\Sigma O \Phi I \Sigma T I K H$, The Sophistic Movement (1984), 233-41, then it is difficult to see how the ensuing argument would work. It could have the structure: (i) if it had happened then XYZ would have happened, (ii) but XYZ could not have happened, (iii) therefore it did not happen, but in this case the conclusion would be that it did not happen, not that Palamedes would not have been able, which is the expressed aim. L. Càffaro, Encomio di Elena; Apologia di Palamede (Florence, 1997) suggests that the initial hypothesis is 'Palamede è un traditore' (Palamedes is a traitor), which cannot be right for the same reason that the argument would no longer be aimed at the explicit conclusion that Palamedes was not able. This conclusion is explicit not only in the way the argument is introduced but also in the way it ends in (12): 'Thus it would have in fact been entirely impossible for me to 
(i) if it had been possible for a Greek to do it, then XYZ would have been needed,

(ii) but XYZ would not have been possible

(iii) therefore, it would not have been possible for a Greek to do it

(iv) therefore, a fortiori, Palamedes would not have been able [claim (a)]

Understanding the structure in this way also fits well with the series of potential optatives that follow in the ensuing argument.

As mentioned above, there are ten distinct arguments in this section that fill out the 'XYZ' in premises (i) and (ii) above in different ways. The first argument (6-7) fills them out as follows:

(a) if the crime were possible, then it would have been possible for Palamedes to communicate with the Trojans

(b) if communication was possible, it was possible either one-on-one or with a third interpreter

(c) either way would not have been possible (since they do not speak the same language and an interpreter would have added another witness)

(d) therefore, communication would not have been possible [by (b)-(c)]

The ensuing arguments follow the same pattern (see the appendix for a complete summary). They each take the form of conditional polylemmatic reductiones, with a

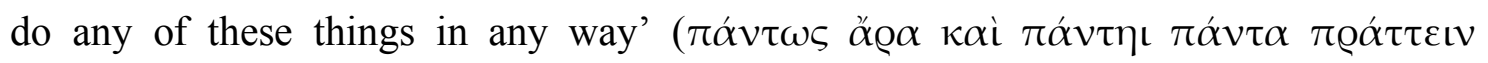

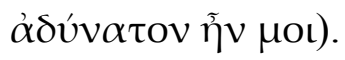


series of nested polylemmatic divisions conditional on the treason being possible. Negative results in each case provide a reductio of that possibility.

An analogous structure can be found in the next part of the Palamedes. Gorgias has Palamedes offer another polylemmatic reductio, this time for claim (b) that, even granting his ability to commit treason, he would not have been willing (13-19). It begins with a large polylemma as in the Helen, with six options considered. And once again we see the same nesting of one polylemma within another as diagrammed in the appendix. This general pattern, and more specifically the use of a nested, polylemmatic reductio, resurfaces in the first part of On Not-Being.

\section{§2: THE FIRST PART OF ON NOT-BEING}

When it comes to the first part of On Not-Being, there are significant structural differences in the surviving paraphrases. Both include roughly the same number of arguments, ${ }^{18}$ but their order and internal relations differ. In Sextus' version the argument structure is laid out explicitly and systematically as a nested polylemmatic reductio. The $M X G$, on the other hand, has three independent arguments: it begins with two arguments that are said to be Gorgias' own ('íıov, 979a23), criticizes them, then puts forward a separate polylemmatic reductio whose elements are said to be borrowed from others (specifically Zeno, Melissus, and Leucippus). These differences are best explained by

\footnotetext{
${ }^{18}$ The correspondence is only rough, and partly influenced by the natural impulse to try to identify arguments from each version with one another. Still there are clear cases of arguments that appear in only one of the two paraphrases, for instance Sextus (75-76) and $M X G 980 \mathrm{a} 3-8$. For an outline of the similarities and differences between the arguments in the first part, see p. 000 below.
} 
the hypothesis that Sextus' version is closer to the original structure and that Anonymous rearranges its arguments in the $M X G$. To show this, it will be important to analyse the structure of each paraphrase separately.

\section{§2.1: Sextus'version: a nested polylemmatic reductio}

Sextus' version of the first part of On Not-Being contains a nested polylemmatic reductio much like that of the first two parts of the Palamedes and their positive counterpart in the Helen. This structural similarity is part of why Sextus is the more likely candidate for preserving the original argument's structure. ${ }^{19}$

After an initial introduction that sets out the tripartite structure of the whole treatise, Sextus summarizes the argument of the first part as follows:

(66) First, then, that nothing is, he concludes in the following way: if indeed anything is, then either being or not-being is, or both being as well as not-being

${ }^{19}$ One might worry that, even before addressing the structure, one needs to make better

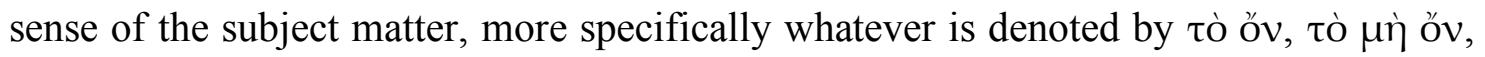
and عĩvaı more generally. These are familiar challenges in interpreting the Eleatics as well, though in Gorgias' case there is the extra complication that Sextus is possibly rephrasing Gorgias' initial terminology. In the end, however, these issues will not affect the way one understands the underlying method indicated by Sextus' paraphrase. For recent discussions of how best to understand the verb 'to be' in Greek philosophy, see C.H. Kahn, 'A Return to the Theory of the Verb be and the Concept of Being', Ancient Philosophy 24 (2004), 381-405 and L. Brown, 'The verb “to be” in Greek philosophy', in S. Everson (ed.) Language: Companion to ancient thought 3 (Cambridge, 1994), 21236. 
is. But neither is it the case that being is, as he will establish, nor not-being, as will be explained, nor being and not-being, as he will prove even this. Therefore it's not the case that anything is. ${ }^{20}$

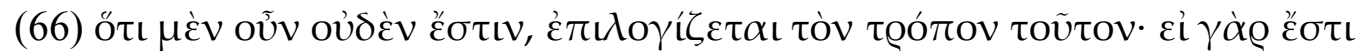

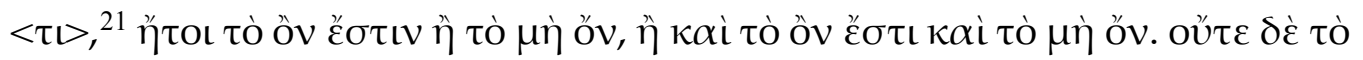

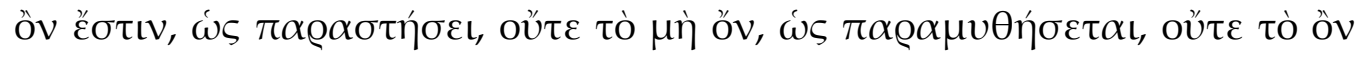

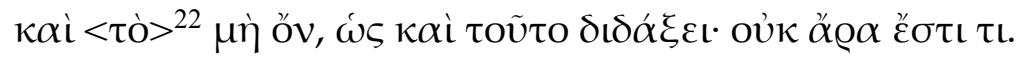

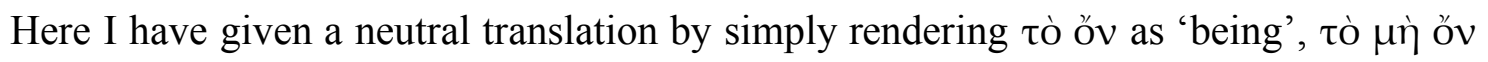
as 'not-being', and forms of the verb Eĩv $\alpha \iota$ with a simple 'is' (leaving any extra supplement implicit as it is in the Greek). The advantage of the translations 'being' and 'not-being' is that they preserve the participial form of the original, making it easier to

${ }^{20}$ I understand Sextus to be using the conclusion in the final clause here, 'it's not the case that anything is', interchangeably with the conclusion stated at the beginning of this section as well as the end of (76), 'nothing is'.

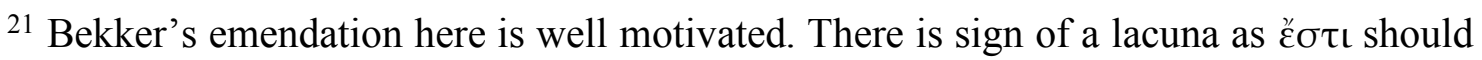

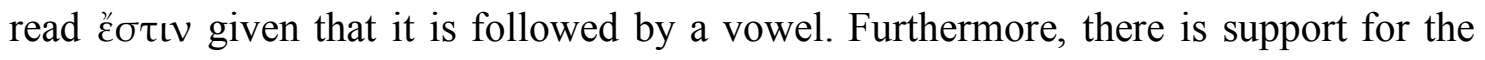

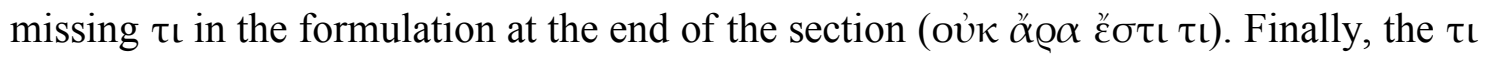
could have easily dropped out due to haplography.

${ }^{22}$ It is likely that tó has dropped out of the manuscripts since, when this option is picked

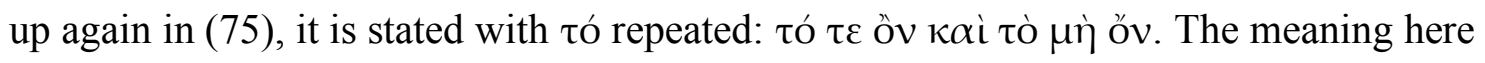
must be 'being and not-being' as I have translated rather than 'that which is and is not' as the Greek without the second tó would suggest. 
distinguish this construction from finite uses of the verb. ${ }^{23}$ What is clear, and is most important for our purposes, is that this sets up the overarching structure of a conditional polylemmatic reductio, with three exhaustive options conditional on there being anything whatsoever (see the appendix for a diagram of this structure). Thus the force of the reductio is to show that nothing whatsoever is. ${ }^{24}$

${ }^{23}$ Kerferd prefers the translations 'that which is' and 'that which is not' because they allow for a more indefinite reading of the subject in either case, allowing that any theoretical construct of previous thinkers could be substituted $(14-16,22)$. I take it that Kerferd supposes 'being' and 'not-being', by contrast, to indicate definite concepts that do not allow this indefinite substitutable reading, though I do not think that we have clear concepts corresponding to the terms in English to preclude this reading. I intend to use 'being' and 'not-being' as placeholders that are ambiguous between the definite (single concept) and indefinite (schema for inserting any construct) readings.

${ }^{24}$ One might worry, however, that the third option is redundant. This option immediately stands out as somewhat odd; the first two options appear to be contradictories, in which case they alone exhaust logical space. Surely they are at least contrary to one another, in which case we should know in advance that both cannot obtain at once. If they are neither contrary nor contradictory, then it becomes hard to see how the three options listed are meant to be exhaustive in the first place. It is possible that Sextus or even Gorgias recognizes the redundancy, as hinted at by the rather emphatic 'he will prove even this'

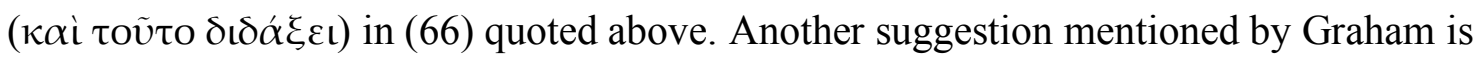
that the conjunctive case is a direct response to the Atomists, who thought that the world was made up of both atoms (being) and void (not-being). While this option is strange, 
In the remainder of the first part as reported by Sextus, each of the three options is systematically refuted, thus completing the reductio as set out in the introductory section. Interestingly, the sequence of arguments against the claim that being is mimics the overarching structure of the first part, thus creating a structure of nested polylemmata as in Gorgias' other works. Once again the structure is laid out explicitly:

(68) And next, neither is it the case that being is. For if being is, then it is either eternal or generated or eternal and generated at the same time. But neither is it eternal nor generated nor both, as we will show. Therefore it's not the case that being is. For if being is eternal...

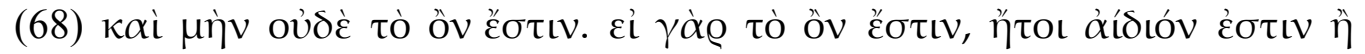

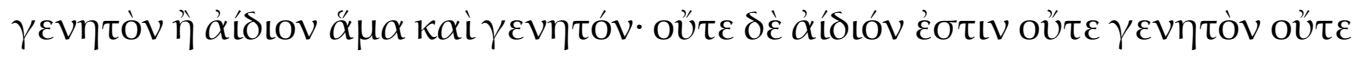

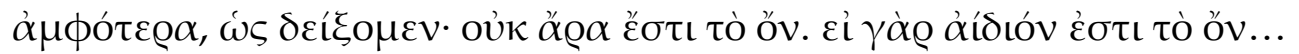

The parallel with (66) is quite close. This creates a nested polylemmatic reductio, as can be seen in the argument structure diagrams in the appendix.

One of the most puzzling sections is the intervening reductio of the not-being option in (67). In $\S 2.2$ I will argue that the complications of this section help explain how Anonymous might have misunderstood the overarching argumentative structure. For this reason, a closer look at (67) is in order. The main takeaway will be that the argument consistently requires understanding a wide-scope negation, though there is one intentional slippage at the beginning. The difference is important; the narrow-scope

and perhaps self-consciously so, the overarching structure of a conditional polylemmatic reductio is still quite clear. 
claim 'not-being is not' is not strictly warranted by the argument, which instead supports the wide-scope claim 'it's not the case that not-being is' ${ }^{25}$ The section runs as follows: (67) And indeed not-being, to begin, is not. ${ }^{26}$ For if not-being is, it will be and will not be at the same time: for in so far as it is conceived as not being, it will not be, and insofar as it is not-being, it will in turn be. But it is entirely out of place $^{27}$ for something to be and not to be at the same time. Thus it is not the case that not-being is. ${ }^{28}$ And alternatively, if not-being is, being will not be: for these are opposite to one another, and if to be goes along with not-being, not to be will

${ }^{25}$ To see the difference, compare the claims 'it's not the case that all roads are ploughed' and 'all roads are not-ploughed'. The latter is equivalent to 'all roads are unploughed' and is not consistent with there being any ploughed roads. The former, however, leaves open the possibility that some roads are ploughed while others are not.

${ }^{26}$ Here is the intentional slippage where the negation is narrow-scope (in the Greek, ov $\kappa$

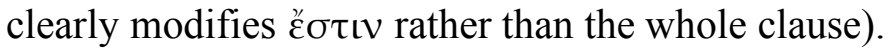

${ }^{27}$ I have translated ärotrov literally as 'out of place', but the force in the Greek is stronger than that of the English: this is not merely to say that it would be strange or surprising, but rather illogical or bizarre enough to warrant a reductio.

${ }^{28}$ The negation is ambiguous between a wide-scope reading and a narrow-scope reading;

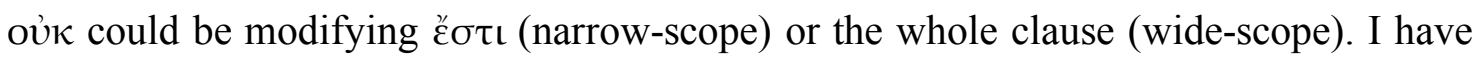
gone with the wide-scope translation strictly warranted by the argument, though again the ambiguity may be intentional. 
go along with being. But it's not at all the case that being is not; nor then will notbeing be. ${ }^{29}$

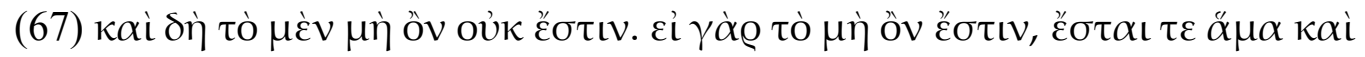

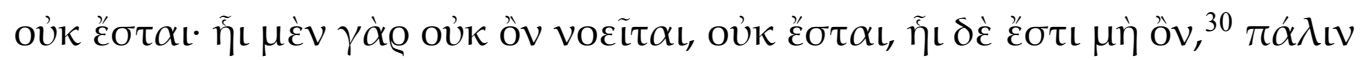

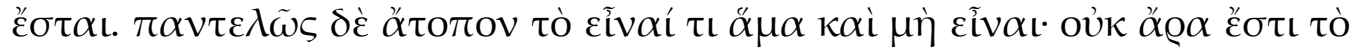

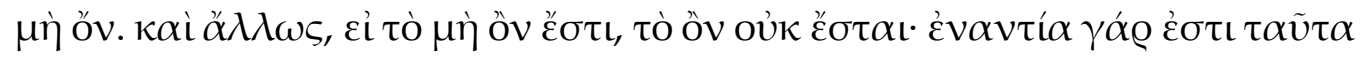

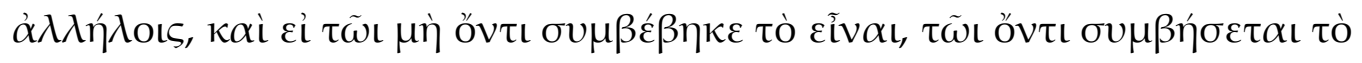

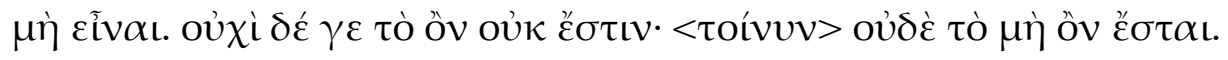

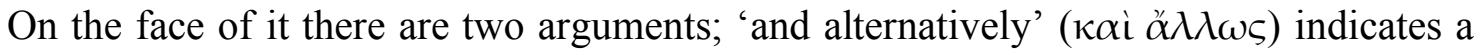
transition from one argument to another. ${ }^{31}$ But there is a puzzle as to how exactly they relate to one another. The transition suggests that they are two arguments for the same conclusion, which is further supported by the similarity of structure in both arguments; both begin with the hypothesis 'if not-being is' and give a reductio against that hypothesis. Yet they do not appear to state the same conclusion. The first conclusion is put in narrow-scope terms, 'not-being is not', and the second in wide-scope terms, 'it's not the case that not-being is'.

${ }^{29}$ Here the negation is unambiguously wide-scope (oủoć modifies the whole clause).

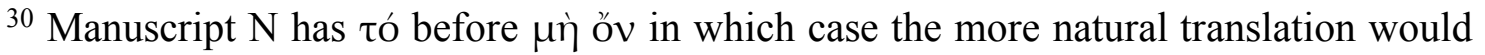
be 'in so far as not-being is'.

${ }^{31}$ Another clear example of $\kappa \alpha i z \alpha \lambda \lambda \omega \varsigma$ indicating an alternative argument for the same conclusion occurs at the beginning of (73). 
Strictly speaking, both arguments appear to license only the wide-scope version of the claim. ${ }^{32}$ Thus it is more plausible to read both as arguments for the same conclusion. But if this is right, then why the switch? The pattern of narrow-scope vs wide-scope claims throughout this part of the text gives us some traction. ${ }^{33}$ In general, explicitly narrow-scope claims are infrequent. The polylemmatic reductio structure licenses wide-scope claims, and explicitly wide-scope claims do indeed surface at crucial

${ }^{32}$ Both arguments have the same reductio structure, and a reductio only warrants the wide-scope claim. Using the example from $n .25$ above, if I run a reductio against the claim 'all roads are ploughed' then I have only established the truth of the wide-scope claim 'it's not the case that all roads are ploughed'. Suppose, for instance, that the reductio depends on only the more accessible roads being ploughed while the road to the mountains was skipped; in this case, some roads are ploughed and some are not, warranting the true claim 'it's not the case that all roads are ploughed' but making 'all roads are not-ploughed' false.

${ }^{33}$ It is unlikely to be a simple mistake since Gorgias appears to be sensitive to the distinction between narrow-scope and wide-scope claims in the ensuing argument. The second argument of (66) above dismisses the narrow-scope claim that 'being is not' as part of the reasoning behind denying the claim that 'not-being is'. But the next argument embraces the wide-scope claim 'it's not the case that being is'. To be consistent, Gorgias has to maintain that the narrow-scope claim 'being is not' is false and the wide-scope claim 'it's not the case that being is' is true. He has to be sensitive to the distinction to pull this off. 
junctures in the argument. ${ }^{34}$ So why does (67) begin with the narrow-scope claim? The best explanation is that it is an intentional slippage used to set up the argument in (75). In (75) the target is the conjunctive claim 'both being and not-being are'. The reductio depends on the narrow-scope claim from (67), 'not-being is not':

(75) And that it is indeed not the case that both are, both being and not-being, can easily be concluded. For if in fact not-being is and being is, not-being will be the same as being in so far as their being is concerned; and for this reason neither of them is. For it is agreed that not-being is not, and it has been shown that being stands the same in this respect, thus it too will not be.

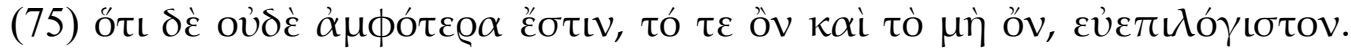

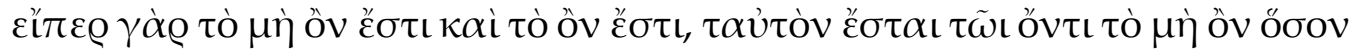

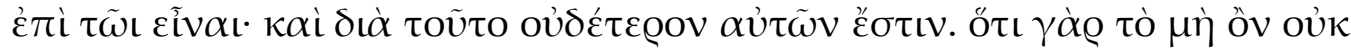

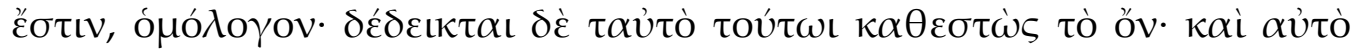

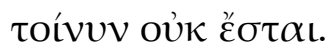

${ }^{34}$ For instance, at the end of (74) the first two prongs of the argument are summarized in explicitly wide-scope terms: 'But indeed, for these reasons it is clear that neither is it the

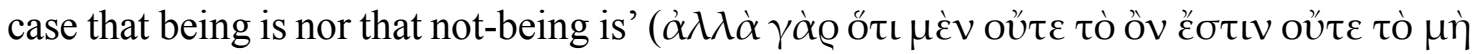

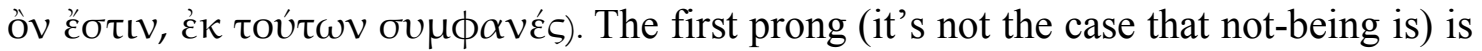
precisely the argument that was made in (67). We then see the same summary in widescope terms at the very end of the argument of the first part in (76): ‘. from which it follows that nothing is. For if neither being is nor not-being nor both, and nothing is

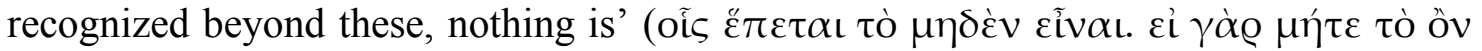

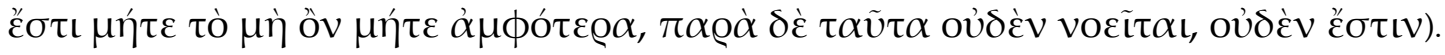


The argument here simply assumes that the narrow-scope claim 'not-being is not' is already agreed upon. ${ }^{35}$ Yet, while it was indeed stated as the conclusion to the first argument of (67), only the wide-scope claim was warranted. This suggests that Sextus (either following Gorgias or on his own) equivocates between the narrow- and widescope claims on purpose; he uses whichever version best fits his current needs (which is the strictly warranted wide-scope claim for most purposes, but the narrow-scope claim for this particular argument). The narrow-scope claim has indeed been mentioned, but technically has not been argued for. Further support would need to be given or it would have to be endorsed on its own for the argument in (75) to go through. ${ }^{36}$

${ }^{35}$ As I understand it, the argument runs as follows:

(i) Assume for reductio that being is and not-being is

(ii) Being and not-being are the same in so far as their being is concerned [by (i)]

(iii) Not-being is not [argued for in (67)]

(iv) If not-being is not, and being and not-being are the same in so far as their being is concerned, then being is not.

(v) Being is not [by (ii)-(iv)]

(vi) Neither being nor not-being is [by (iii), (v)]

(vii) Contradiction [by (i), (vi)]

(viii) Therefore, it's not the case that being is and not-being is [by reductio, (i)-(vii)] 36 This is one way in which the argument in (75) is deficient, though it is not the only oddity. The lemma discussed here, 'both being and not-being are', already seems redundant (see n.24 above). 
Despite this sleight of hand, the arguments in (67) are by no means blatantly fallacious, and the text is actually quite careful with the scope of the negation. The structure is that of two alternative arguments for the conclusion that it's not the case that not-being is, and thus part of the overarching polylemmatic reductio. Yet the structure along with the scope of the claims argued for is misinterpreted by Anonymous, which in part explains why he reorders the arguments in the $M X G$ as I will argue below.

\section{$\S 2.2:$ MXG Version, First Part Rearranged?}

The $M X G$, too, reports a polylemmatic reductio, though one that is much less intricate than those surveyed so far. It also reports two separate arguments whose counterparts in Sextus play a subsidiary role as part of the polylemmatic reductio instead (see the appendix for a comparison of the two structures). Below I begin with a series of detailed observations about the similarities and differences between the two versions, then offer a hypothesis that explains them.

Two unique features of the $M X G$ version immediately stand out. First, Anonymous shows a keen interest in the provenance of Gorgias' arguments. The first part of the $M X G$ begins as follows:

And to begin that [nothing] is, ${ }^{37}$ he puts together the things that have been said by others, as many as say opposite things about the things that are...

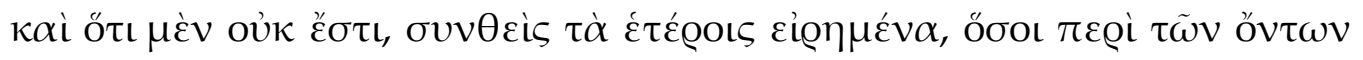

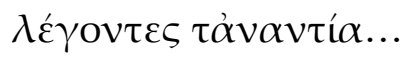

(979a13-15)

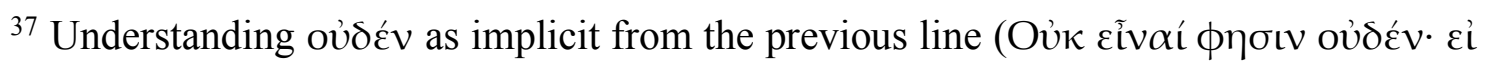

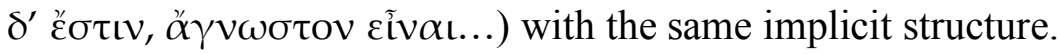


Unlike Sextus, Anonymous emphasizes that the argument of the first part involves borrowing opposed arguments from others. He continues to stress this point by identifying the origins of different arguments. After a brief summary of the part of the argument that borrows most heavily from others, Anonymous notes:

some he sets out to show as Melissus does, others as Zeno, after his own first display...

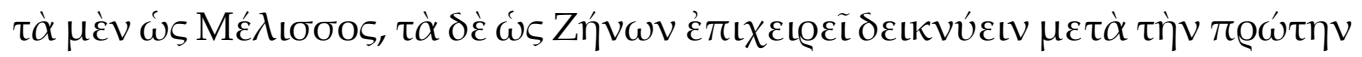

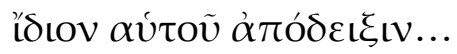

He goes on to give Gorgias' original arguments. Next, he sets out the arguments borrowed from others where he again mentions Melissus (979b22) and Zeno (979b25, 37 ) and adds 'the so-called arguments of Leucippus' (980a7). None of the arguments in this latter group are explicitly said to originate from Gorgias himself. The arguments as he reports them are divided between first those that are original to Gorgias, and later those that are not.

The second peculiar feature of the $M X G$ is that it offers a critique of the arguments that are original to Gorgias. Anonymous criticizes those arguments immediately after considering them, before moving on to those that are borrowed from others (he does not criticize the latter).

Despite these obvious differences, there are obvious similarities as well. Most of the arguments of the $M X G$ version appear to have a close parallel in Sextus' version. ${ }^{38}$

\footnotetext{
${ }^{38}$ The clearest exception is the final argument in the $M X G$ version that nothing is moved (980a1-8) which does not have a parallel in Sextus' version.
} 
Below is a list of what I take to be the main arguments attributed to Gorgias' On NotBeing by the $M X G$ version, with references to each counterpart in Sextus:

(1) first original argument that nothing is (979a25-31)

a. similar to the first argument against the claim that not-being is in Sextus (67) in that both are based on the hypothesis that not-being is not-being:

i. $M X G$ : 'For if not-being is not-being, not-being would be no less

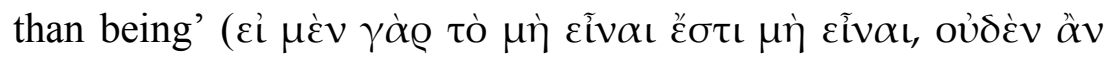

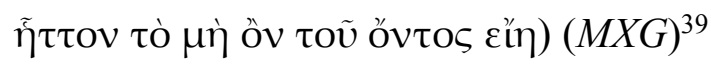

ii. Sextus: 'For if not-being is... insofar as it is not-being, it will in

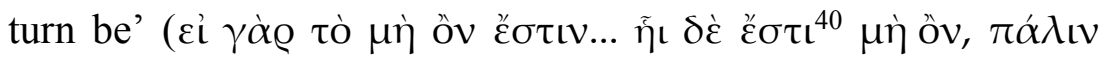

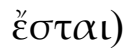

b. similar to the second argument against the claim that not-being is in Sextus (67) in making the inference that being is not by a principle of opposites:

i. $M X G$ : 'But still if not-being is, being, he says, is not, that is the

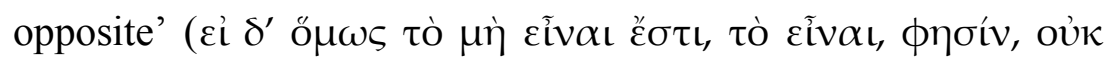

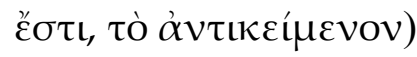

\footnotetext{
39 Alternatively, one might understand the final clause as carrying over the previous subject and containing a complete use of the copula rather than an incomplete use as I have translated it (and as found in Sextus). In this case the translation would be '[notbeing] would be not-being no less than being'. Either way, however, the hypotheses and the reductio structure appear to be the same.

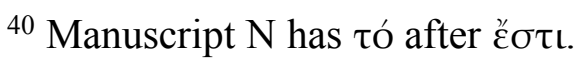


ii. Sextus: 'if not-being is, being will not be: for these are opposite to

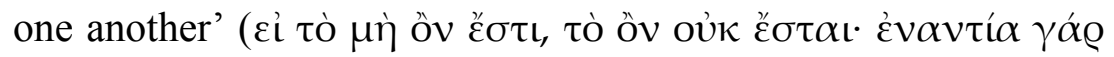
$\dot{\varepsilon} \sigma \tau \iota \tau \alpha \tilde{v} \tau \alpha \dot{\alpha} \lambda \lambda \eta \dot{\lambda} \lambda \iota \varsigma)$

(2) second original argument that nothing is (979a31-3)

a. similar to the second argument against the conjunctive claim 'both being and not-being are' in Sextus (76) in that both rely on the hypothesis that being and not-being are the same:

i. $M X G$ : 'nothing would be, unless being and not-being are the same,

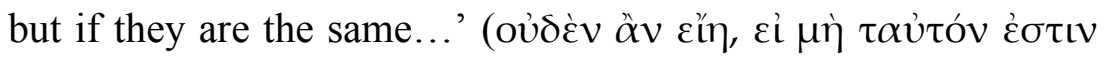

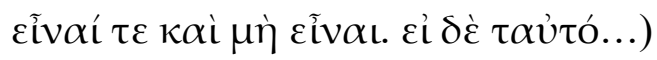

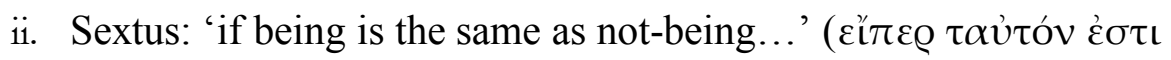

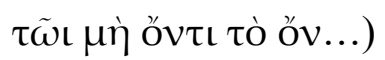

(3) argument against it being ungenerated ( $\dot{\alpha} \gamma \dot{\varepsilon} \nu \eta \tau o v, 979 b 21-6)$

a. Similar to Sextus' argument against it being eternal (áíóov, 68-70) in making the inference that it is unlimited ( $\ddot{\alpha} \pi \varepsilon$ Łoov in both cases), that it is neither in itself ( $\dot{\varepsilon} \vee \alpha \dot{v} \tau \tilde{\omega} \iota$ in both cases) or in another, and that it is

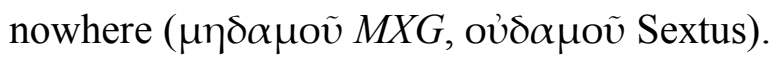

(4) argument against it coming to be ( $\gamma \varepsilon v o ́ \mu \varepsilon v o v, 979 b 26-33)$

a. Similar to Sextus' argument against it being generated $(\gamma \varepsilon v \eta \tau o ́ v, 71)$ in using the same dilemmatic reductio structure, ruling out that it could come either from being or from not-being: ${ }^{41}$

${ }^{41}$ While both versions have the same structure, the reasons given against it coming from being are substantially different. I will set aside the question of which is more accurate 
i. $M X G$ : 'For nothing comes to be either from being or from not

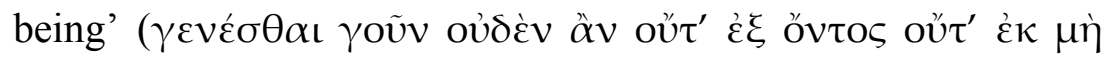

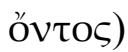

ii. Sextus: 'For if it has come to be, it has come to be either from

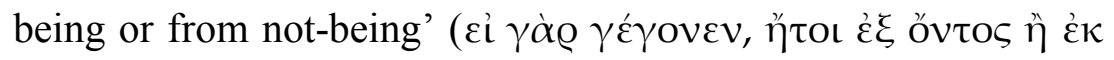

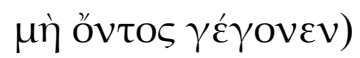

(5) argument against it being either one or many (979b35-980a1)

a. Similar to Sextus' argument against it being either one or many (73-4):

i. $M X G$ : 'if it is neither one nor many, nothing would be' ( $\varepsilon \grave{\imath} \delta \dot{\varepsilon} \mu \eta ́ \tau \varepsilon$

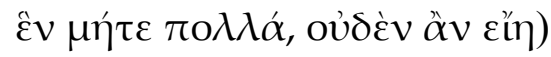

ii. Sextus: 'it is neither one nor many, as will be established:

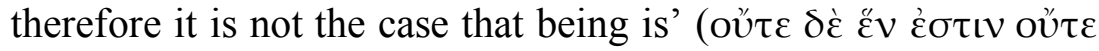

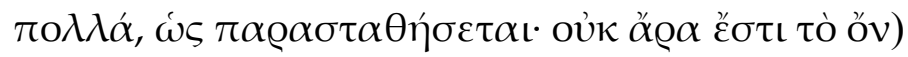

While the parallels are clear, they also reveal how the overarching structure differs. The order in which arguments are offered, the implied connection between different arguments, and the stated conclusion of each one taken on its own all vary significantly.

These differences are most pronounced in the first two arguments attributed to Gorgias. The first argument in the $M X G$ has an affinity with the first argument in Sextus, but the second argument is in fact the second to last argument in Sextus' version. In the $M X G$, both are arguments for the main conclusion that nothing is. ${ }^{42}$ In Sextus, however,

to Gorgias' original in substance for present purposes; it will not affect the similarities and differences in structure that I am interested in here.

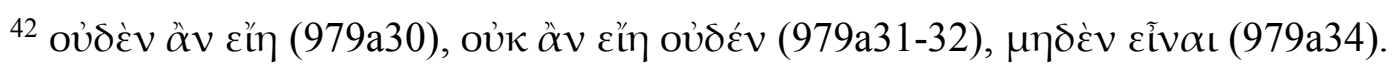


neither is aimed at the main conclusion; each simply rules out one arm of an initial trilemma. The first is an argument against the possibility that not-being is and the second an argument against the possibility that both being and not-being are. ${ }^{43}$ On this version, Gorgias is not entitled to conclude that nothing is until he has also argued against the third possibility, that being is, which in fact occupies most of Sextus' paraphrase. Anonymous takes these first two arguments to be parallel to those he classifies as borrowed from others and therefore redundant. Sextus takes them as complementary arguments that are essential for drawing Gorgias' overarching conclusion.

There is a much closer similarity in the arguments that the $M X G$ classifies as borrowed from others, and they appear in the same order as in Sextus. But again there is a difference in the stated conclusions. Both versions preserve two alternative arguments for the same conclusion, one based on a division between generated and ungenerated, the other based on a division between one and many. In the $M X G$ version, the conclusion of each is 'nothing is' ${ }^{44}$ But in Sextus the conclusion is 'it's not the case that being is'. Once again, Anonymous understands these as alternative arguments for the main conclusion that nothing is, while Sextus understands them as alternative arguments for an intermediate conclusion, one that only licenses the main conclusion when taken in conjunction with two other limbs of a trilemma. Anonymous does not report this overarching trilemmatic structure, instead seeing three alternative arguments for the same conclusion.

\footnotetext{
${ }^{43}$ These are the arguments detailed in the previous section.

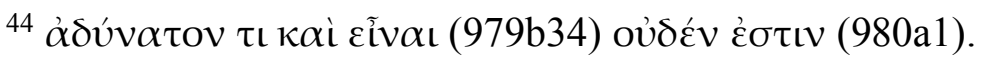


Spatharas offers an explanation for this discrepancy in his commentary (294-8, 364). He maintains that the $M X G$ version is closer to the original and Sextus rearranged the arguments to separate those that had to do with being and not-being from those that had to do with a combination of the two. 'The effort on behalf of Sextus to present a smoother and more "logical" arrangement', he says, "may be taken as a sign that $M X G$ is closer to the original, Gorgianic arrangement' (298). On the contrary, I propose that the opposite is true: Sextus' version is closer to the original. This makes On Not-Being more consistent with the logical structure of Gorgias' other works; appealing to intervention by Sextus is not necessary to explain the structure of a polylemmatic reductio. As we will see, my hypothesis also explains why the $M X G$ differs with evidence internal to the text itself: Anonymous' explicit interest in provenance and a confusion concerning wide vs narrow-scope negation.

Because Anonymous seems particularly interested in where Gorgias' arguments come from, it makes sense that he might have reordered them so as to group together first the arguments that are Gorgias' own and second those he borrowed from others. This would only require one small change: fronting Gorgias' original but puzzling argument concerning the conjunctive claim that both being and not-being are. On my hypothesis, Anonymous moved it next to Gorgias' other original but again rather puzzling argument against the claim that not-being is. In fact, this hypothesis makes good sense of a line that otherwise has puzzled commentators. Just after what the $M X G$ reports as Gorgias' second original argument (which again, on my hypothesis, is transposed from the end of the argument) Anonymous says: 
This then is the same argument as the former one. ${ }^{45}$

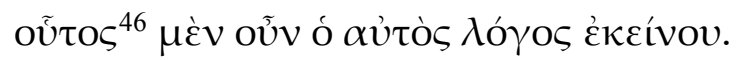

This line has caused problems for interpreters. Untersteiner and Buchheim both follow

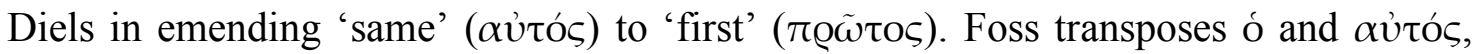
which may be what Dillon and Gergel have in mind when they translate: 'Such, then, is

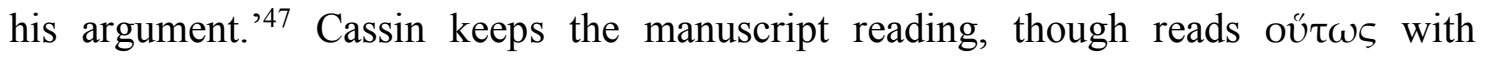
manuscript R. On Cassin's rather optimistic interpretation, Anonymous tells us that he is using the very same words, not only the same general sense, as Gorgias does in the original (445-7). Yet I take this line to say that the second of the two arguments is the same in that it argues for the same conclusion as the first. It makes sense that Anonymous might have included this as a justification for moving the second argument here from its original location.

This is a mistake: Anonymous confuses what are really two separate limbs of a trilemma for two arguments for the same conclusion. His mistake in identifying the overall aim is enabled by mistakenly treating it as the narrow-scope rather than the widescope conclusion. Anonymous thinks that Gorgias shows that nothing is by establishing the narrow-scope claim that each thing (not-being included) is not. When he asks: 'but if

45 Taking èké́vov as a genitive of connection or comparison (Smyth 1417, 1431).

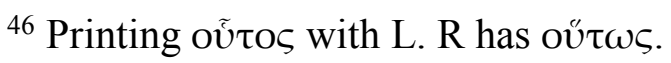

${ }^{47}$ H.E. Foss, De Gorgia Leontino commentatio, (Halle, 1828); Dillon \& Gergel, at 71. 
it is thus, why does it follow that all things are not rather than are?'48 he betrays his narrow-scope understanding of the conclusion. He rightly points out that the narrowscope claim 'each thing is not' is not warranted by the argument, but wrongly sees it as aimed at this narrow-scope claim rather than the wide-scope claim 'it's not the case that not-being is' that it actually warrants. Anonymous jumps the gun by assuming that this argument alone is meant to license the overarching conclusion, a confusion further confirmed by the fact that he helps himself to the claim that being is (which Sextus acknowledges needs to be denied independently) in offering his criticism (979b10). This confusion about the scope of the negation enables his reordering of the original argumentative structure.

Thus the hypothesis that Sextus remains more faithful to the structure of the first part of Gorgias' On Not-Being makes good sense of both texts as they have come down to us, especially as concerns the similarities and differences observed above. Anonymous makes one small change in the order of argumentation, moving what he takes to be Gorgias' second original argument to the beginning out of an interest in grouping it with Gorgias' other original contribution. Because he misunderstands the scope of the negation he sees this as one of three independent arguments for the same conclusion, meaning that the order of presentation does not matter. Sextus, on the other hand, accurately sees the overarching trilemmatic structure and preserves the original ordering.

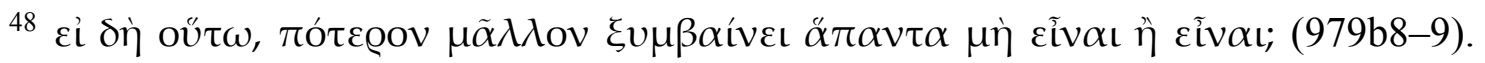

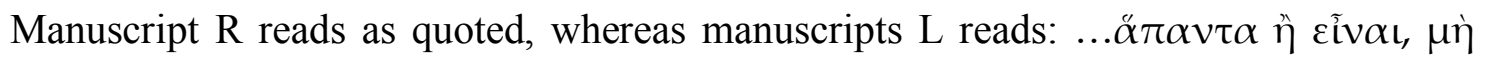
عĩvat. 
So why not think, along with Spatharas, that the $M X G$ more accurately preserves the structure of the original, that Anonymous' criticisms are justified, and that Sextus cleaned up this structure himself? Of course we cannot know for sure, and it is possible that Sextus was the one who rearranged the argument. Yet it is equally possible that it was this nuanced structure of the original, at least in part, that drew Sextus to Gorgias' argument in the first place. Furthermore, it seems equally likely that Anonymous could have changed the argument to suit his own preferences. Mansfeld points out how

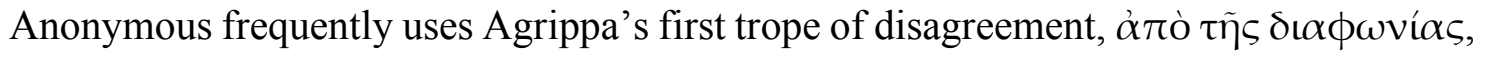
throughout the treatise, and how Anonymous' interpretation of the first part of Gorgias' argument puts much emphasis on this same trope. ${ }^{49}$ But it could equally be that Anonymous was misled by his own argumentative technique and, seeing something similar in Gorgias, read it as Gorgias' main technique. Since these 'bias towards philosophical predilection' arguments can cut either way, they should carry little weight in deciding which structural features are or are not Gorgias' own. More weight should be given to the greater resemblance of Sextus' argument to Gorgias' nested polylemmatic reductiones in other works and to the evidence internal to the $M X G$ that suggests a misunderstanding in the scope of the negation fuelled by an interest in provenance.

49 J. Mansfeld, 'De Melisso, Xenophane, Gorgia: Pyrrhonizing Aristotelianism', Rheinisches Museum für Philologie 131(1988), 239-76 at 249-53. I take this possibility that Anonymous rearranged the argument to fit one of his favourite tropes and the possibility that Sextus rearranged the argument to fit his logical proclivities to be a wash; we should look to other factors to decide which structure is more accurate as I suggest below. 


\section{CONCLUSION}

These structural considerations show that Sextus' version deserves to be taken more seriously than it has been in recent scholarship; it is likely an accurate portrayal of the overarching structure of Gorgias' argument. Once one does so, a number of other Gorgianic parallels emerge as well.

For example, the argument from the end of (68) to (70) begins with a string of hypotheticals: if it is eternal, it has no starting point, if it has no starting point, it is unlimited, if it is unlimited it is nowhere. The first argument of the Palamedes contains a similar string of hypotheticals beginning in (6): if the crime were possible then a discussion would have been possible, if a discussion then communication, if communication then a meeting in person, if a meeting in person then a means of speaking and being understood in person, etc. Furthermore, there is similar wordplay with the term

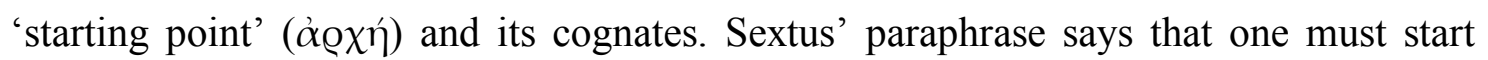
( $\dot{\alpha} \varrho \kappa \tau \dot{\varepsilon} \mathrm{OV})$ with the eternal case, and that in that case there is not any starting point

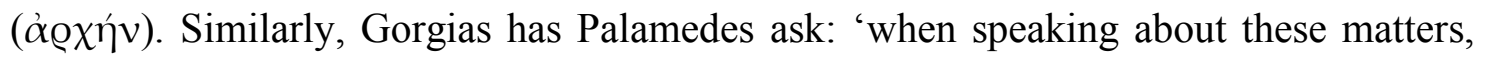
where should I start ( $\alpha \check{\varrho} \varrho \omega \mu \alpha \mathrm{s})$ ?' then begins his defence by stating 'it would have been

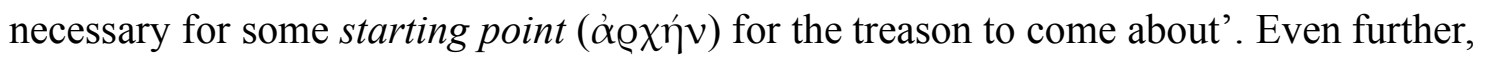
in (70) Sextus states the conclusion of the argument as follows: 'it's not even being in the first place ( $\tau \dot{\eta} v \dot{\alpha} \varrho \chi \eta \dot{\eta} v)$ '. It is hard to see the addition of the rather rare adverbial use of $\dot{\alpha} \varrho \chi \eta v$ here as a mere coincidence. ${ }^{50}$ The similarity both in the wordplay and in the

${ }^{50}$ See LSJ s.v. $\left.\dot{\varrho} \chi \eta \dot{\eta}, 1 . c\right)$. This use of $\dot{\alpha} \supseteq \chi \dot{\eta}$ is attested in Antiphon (5.73), one of Gorgias' contemporaries. 
hypothetical structure is striking; it suggests that Sextus is preserving these elements too from Gorgias’ original.

Towards the end of the first section there is another hint of Sextus preserving genuinely Gorgianic phrasing. In the Palamedes Gorgias uses two logically equivalent but contrapositive statements to emphasize the incompatibility of two properties: statements of the form 'if $\mathrm{p}$ then not-q' and 'if $\mathrm{q}$ then not-p'. He has Palamedes summarize his argument at the beginning as follows: 'I will show that he doesn't speak the truth in two ways: for if I had been willing I wouldn't have been able, nor had I been able would I have been willing to attempt such deeds' (5). ${ }^{51}$ He later goes on to attack Odysseus' testimony directly, ending with the following consideration: 'So if I am wise I didn't do anything wrong, and if I did something wrong I am not wise. Thus on both accounts you would be lying' (26). ${ }^{52}$ Sextus' version of On Not-Being uses this very same technique. In (72) he argues: 'if being is eternal, it has not come to be, and if it has come to be, it is not eternal', ${ }^{53}$ and again in (76) he claims: 'if both [being and not-being] are,

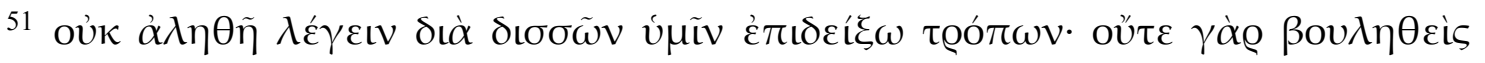

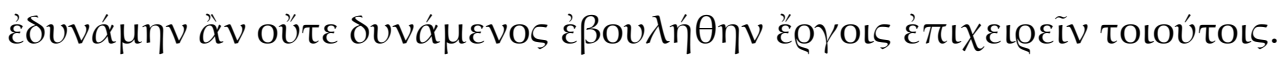

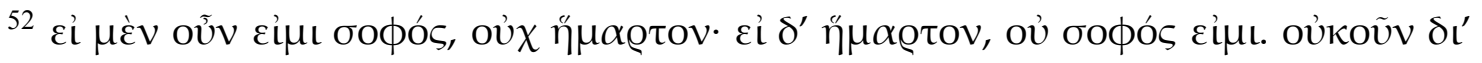

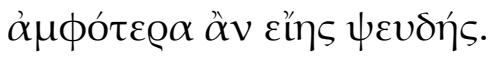

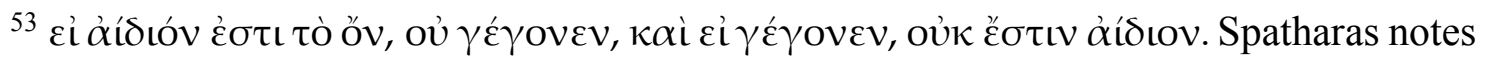
the parallel between Palamedes (26) and Sextus (72) in his commentary at 301. 
they are not the same, and if they are the same, it's not the case that both are. ${ }^{54}$ Once again this suggests that Sextus preserves more of the original argument than is often presumed.

Thus there is much to gain from taking Sextus' paraphrase of On Not-Being more seriously. Despite the fact that he appears to translate much of Gorgias' terminology into the terminology of his own time, there are other respects in which it likely preserves elements of the original that are absent from or obscured in the $M X G$. Yet by no means does it follow that the $M X G$ should simply be ignored. There is no simple dichotomy here; both paraphrases preserve different aspects of the original argument that are worth our attention, and triangulating between them can surely tell us more about what Gorgias' original was really like. It is tempting but inappropriate to dismiss one paraphrase to simplify the already daunting task of making sense of Gorgias' work. Especially when it comes to structural features of the first part, Sextus' version is indispensable for telling us more about Gorgias' overall strategy and for seeing how it fits with a larger pattern of Gorgianic argument.

Idaho State University

EVAN RODRIGUEZ

rodreva2@isu.edu

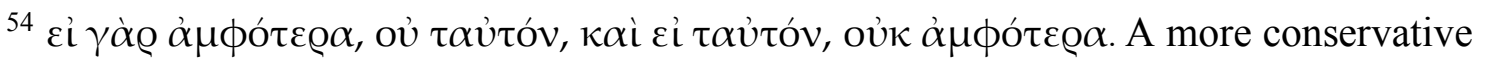
translation might be more accurate in this case even if a bit clunky: "for if "both", then not "same" and if "same", then not "both".'
} 


\section{APPENDIX}

\section{Key for Argument}

\section{Structure Diagrams}

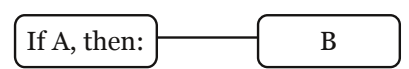

a solid line indicates an inference

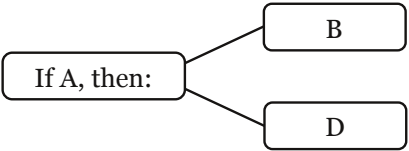

lines emanating from different points indicate alternative inferences

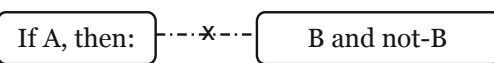

a crossed-out dotted line indicates a reductio (an inference to an unacceptable consequence)

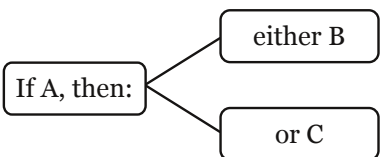

lines emanating from the same point indicate a dilemma or polylemma

\section{Gorgias' Helen}

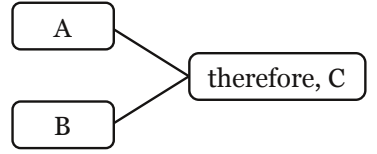

solid lines converging on the same point indicate an inference from multiple premises

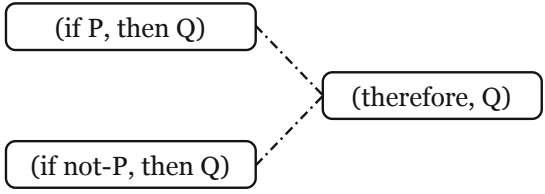

dotted lines converging on the same point indicate an argument by cases, (an argument that derives the same positive conclusion from each of an exhaustive set of alternatives)

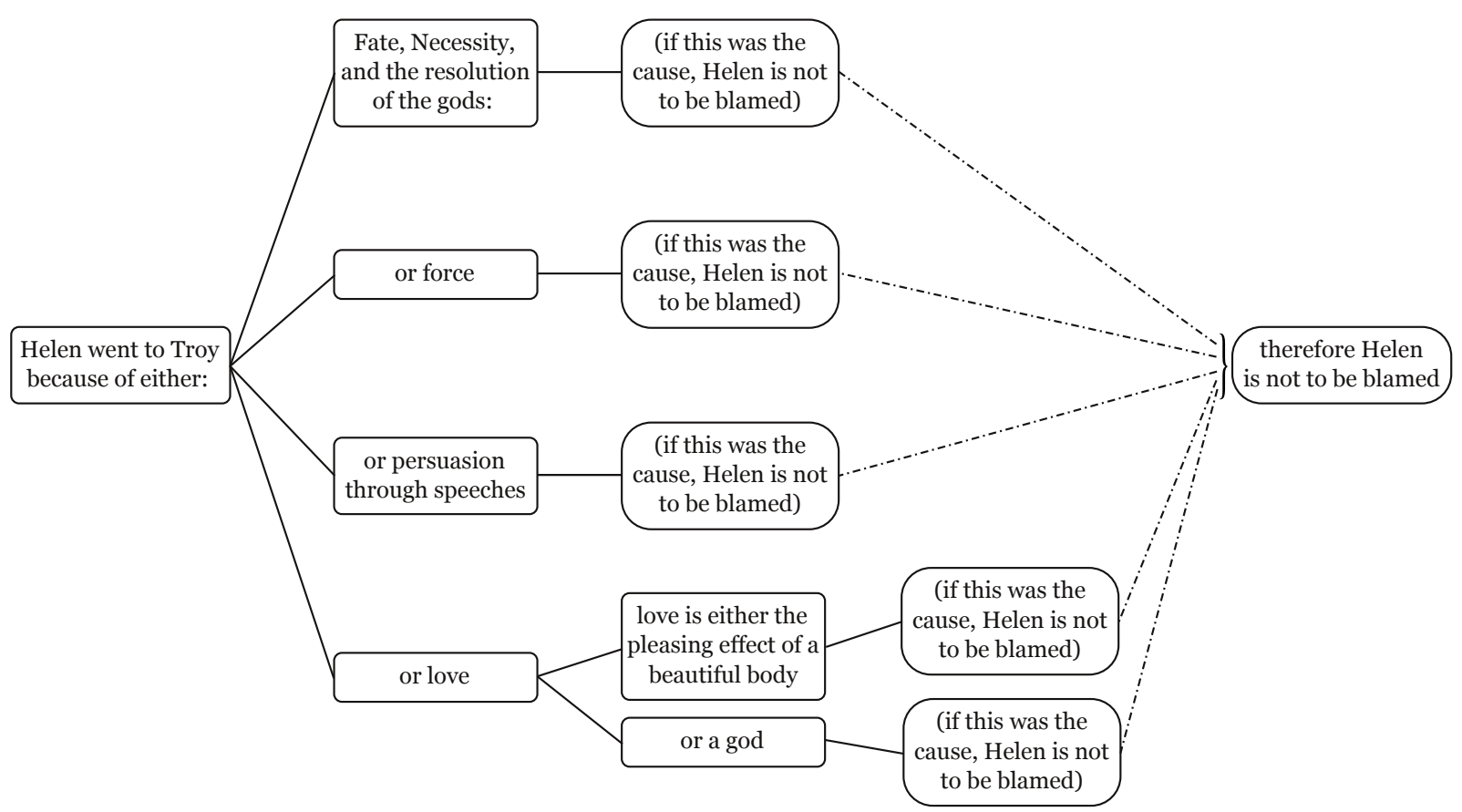




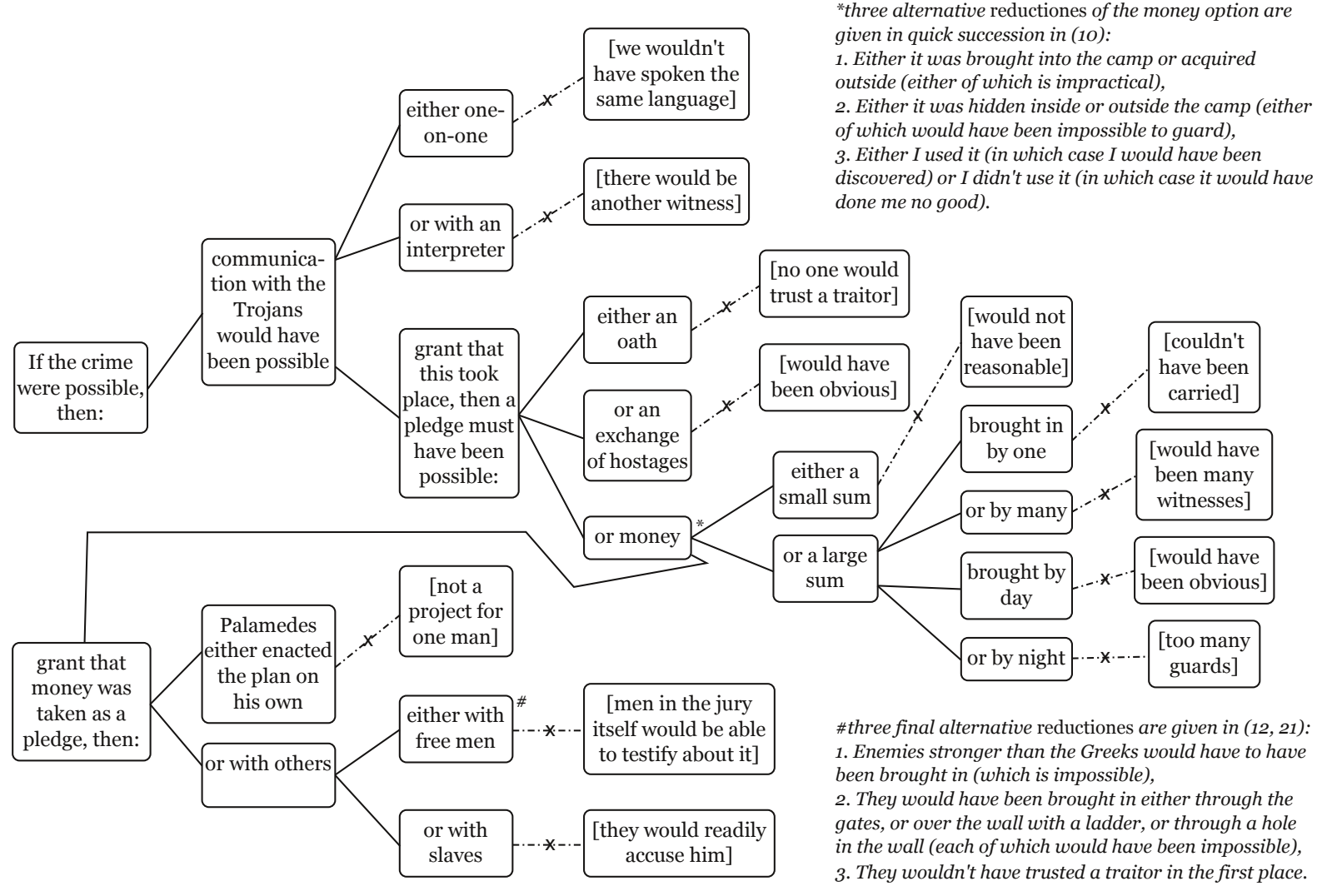

\section{Gorgias' Palamedes, \\ Part 2 (13-19)}

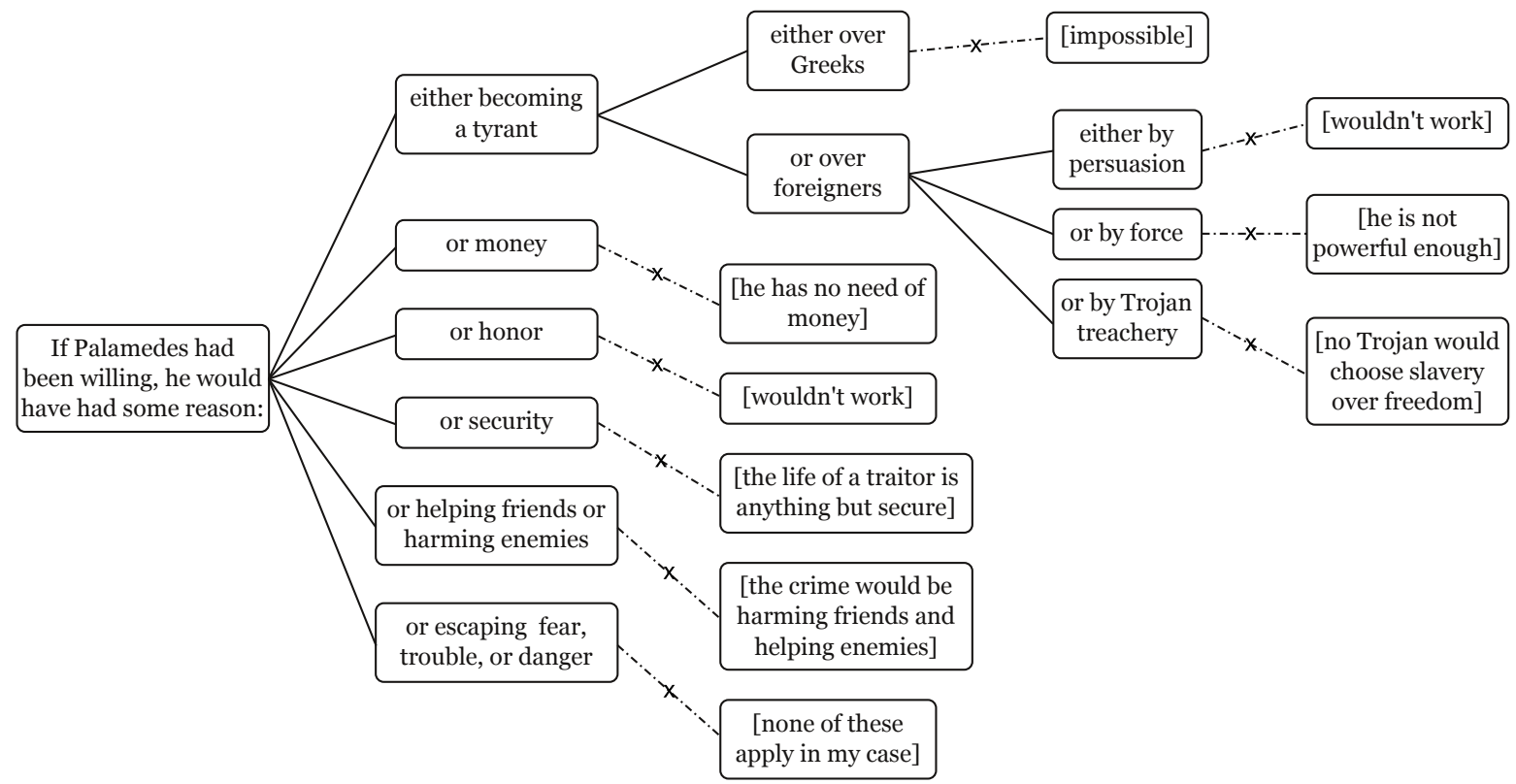


First part of Gorgias'

ONB (Sextus version)

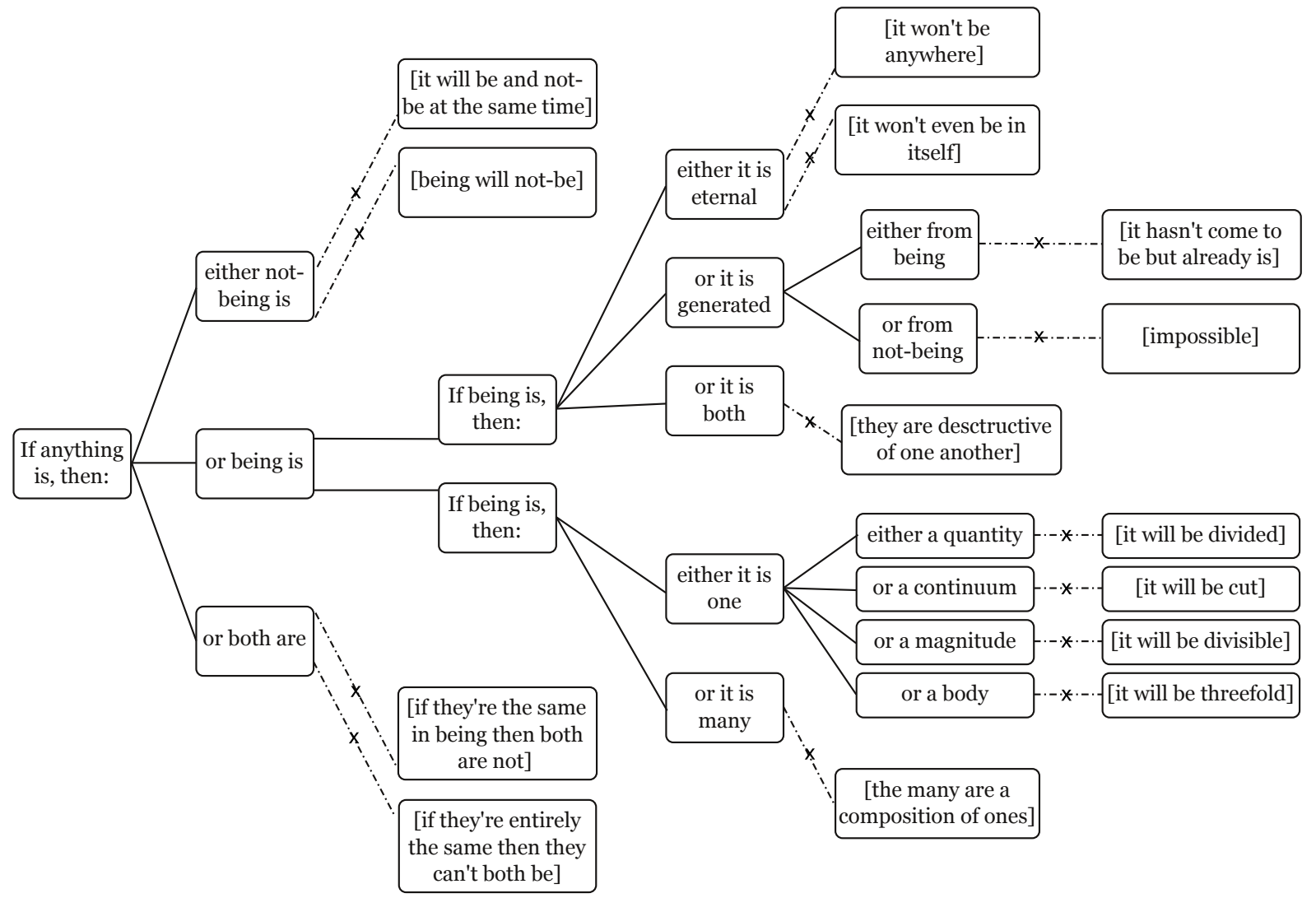

\section{First part of Gorgias'}

ONB (MXG version)

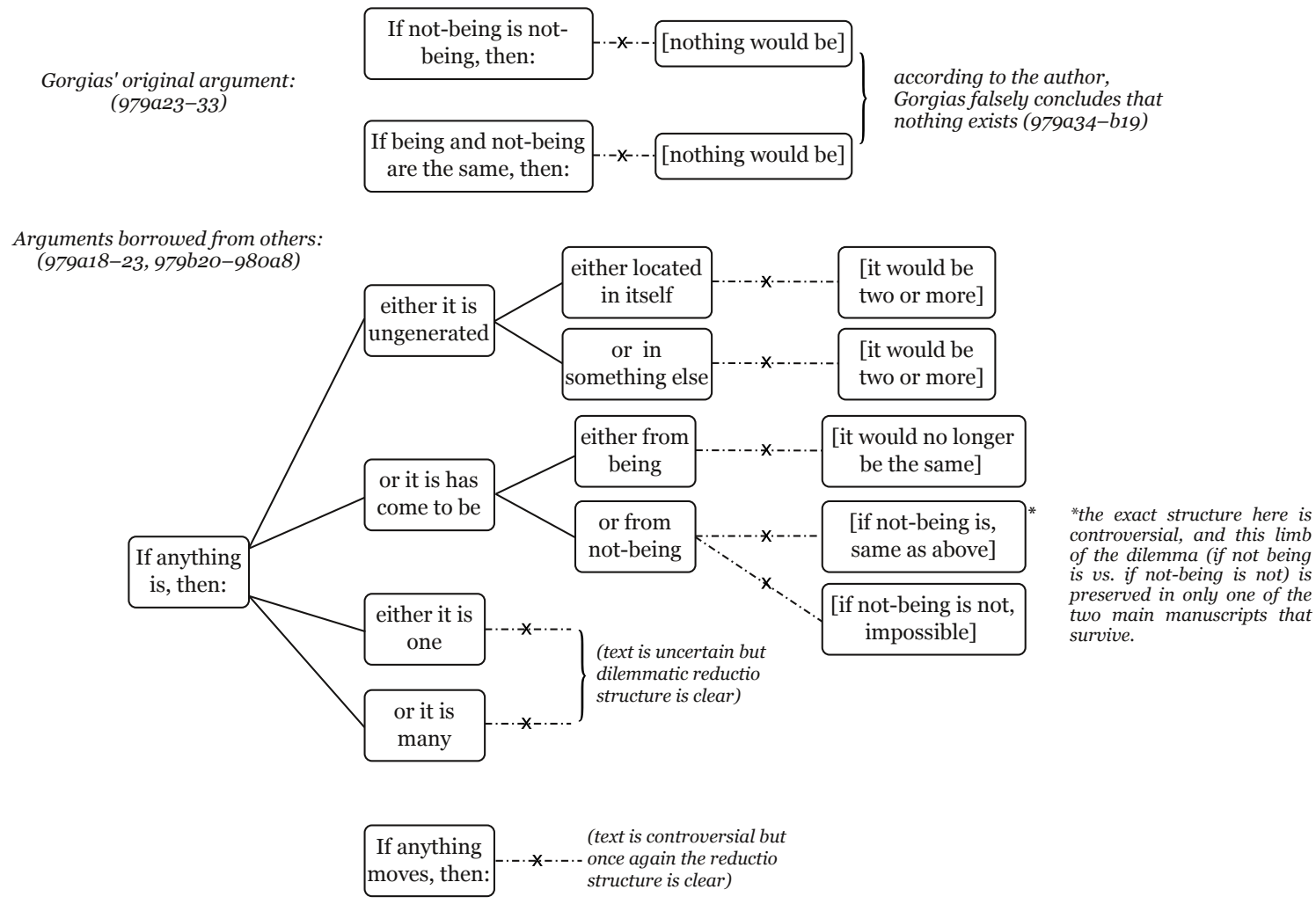

